Assiut Scientific Nursing Journal

http://asnj.journals.ekb.eg

http://www.arabimpactfactor.com

\title{
Impact of Buerger-Allen Exercises on Foot Perfusion and Pain Level for Diabetic Patients Risk with Peripheral Arterial Disease
}

\author{
Inshrah Roshdy Mohammad ${ }^{1}$,Eman Mawed Fahim ${ }^{2}$ \& Eman Hessien Heggy ${ }^{3}$ \\ 1. Assistant Professor of Medical-Surgical Nursing, Faculty of Nursing, Minia University, Egypt. \\ ${ }^{2 .}$ Lecturer of Medical Surgical Nursing. Faculty of nursing .Beni Suif University, Egypt. \\ ${ }^{3 .}$ Lecturer of Medical-Surgical Nursing, Faculty of Nursing, Mansoura University, Egypt.
}

\begin{abstract}
The risk of peripheral arterial disease is markedly increased among individuals with diabetes. The current study aimed to evaluate diabetic patients' foot perfusion and their pain level after applying Buerger-Allen exercises. Subjects \& methods: Quasi-experimental research design was used on a purposive sample of 100 type II diabetic patient in the General medical department and diabetic out-patient clinic, at Minia university hospital. Patients interview questionnair, Ankle-brachial Index test and Numerical pain rating scale were used as tools for data collection. Results: There were highly statistically significant differences between the study group and control group regard Ankle-brachial Index measurements only post-application of Buerger-Allen exercises for six weeks ( $\mathrm{p} \leq$ 0.004). Moreover, results stated that the highest percentage (54.0\%) among the study group who had moderate pain pre-application exercises but after they were performed exercises, their pain description became mild or no pain constituted $(50.0 \% \& 20.0 \%)$ respectively with highly statistical significant. Conclusion: Buerger-Allen exercise was efficient for improvement of lower peripheral arterial perfusion and there are highly statistically significant improvements in pain level among the study group. Recommendations: Diabetic patient must attend health education sessions based on evidence guidelines regard Buerger-Allen exercise which had a positive effect on the improvement of lower peripheral circulation.
\end{abstract}

\section{Keywords: Buerger-Allen, Diabetes, Exercises, Foot Perfusion, Pain Level \& Patient}

\section{Introduction}

Diabetes can affect many extraordinary organ structures inside the body and, additional time can result in serious complications. Most of these complications are vascular, which may be categorized as micro-vascular or macro-vascular. Microvascular complications encompass worried devi ce harm (neuropathy), renal system damage (nephropathy), and eye harm (retinopathy) while, macrovascular headaches encompass cardiovascular d isease, stroke, and peripheral artery disorders (PAD) (American Diabetes Association, 2017). Peripheral arterial sickness or named peripheral vascular disorders (PVD), is a circumstance characterized via a gradual discount in blood flow to 1 or more limbs secondary to atherosclerosis. The danger of PAD is markedly accelerated among individuals with diabetes who had better charges than in comparable non-diabetic populations (Edwards et al., 2017).

Study results conducted in 2010 by (Olin, et al., 2016) who had observed that more than 2 hundred million humans international are residing with Peripheral arterial disease, which represents a $28.7 \%$ elevated occurrence in low- and center-income countries over a ten-12 months duration. Epidemiological studies additionally have confirmed an affiliation between diabetes and an expanded occurrence of PAD that is usually characterized by the occlusive arterial ailment of the decrease extremities. even though many patients are asymptomatic, or had peculiar exceptional symptoms, about one-0.33 experience intermittent claudications, defined as aching, cramping, or numbness inside the affected limb, taking place with exercise and relieved at relaxation (Thiruvoipati et al., 2015). Peripheral arterial disease has a terrible bodily and mental impact on those who were struggling to keep a limb from (CLI) occurrence .important limb ischemia is defined as chronic ischemia inflicting pain at relaxation, ulcers, and or gangrene, which may be attributed to lengthy-standing arterial occlusion (Curry et al., 2018).

Despite initiatives to improve on the identification and management of PAD, the number of people affected and disease morbidity continues to rise. Patients with PAD present across a spectrum of symptoms from asymptomatic to critical limb ischemia (CLI). It is estimated that up to $40 \%$ of patients with PAD report having no obvious exertional symptoms (Gulati, et al 2017). CLI is the most severe manifestation of PAD, the pain at rest which can occur is characterized as an ache or discomfort in the arch of the foot or toes, and it is 
usually exacerbated with leg elevation. Patients are most uncomfortable when lying flat with their legs elevated (McDermott, 2015).

Improve the blood circulation of the lower extremity by exercise has been considered as one of the most effective non-pharmacological management among patients with type 2 diabetes mellitus. There are many techniques to improve foot perfusion such as relaxation technique, warm feet technique and treatments are available to relieve the pain and discomfort of PAD and neuropathy. (GerhardHerman et al., 2017). Lower extremity exercise helps to re-establish collateral blood flow to the legs and the heart. Primary care providers have an inevitable role to assess and diagnose the potential vascular complications of diabetes mellitus in the initial stage. (Dauscher \& Molinaro, 2017).

Buerger-Allen exercise is one of the most common practice exercises in diabetic affected person to empty engorged vessel through the use of postural changes and inspired peripheral circulate by using modulating gravity and making use of muscle contraction for enhancing the lower extremity perfusion amongst diabetic patients which relieve the symptoms in patients with decrease limbs arterial inadequate. Therefore to sell the best of existence Buerger-Allen exercise is wanted amongst patients with type II diabetes mellitus (Patidar, 2018).

Significance of the study:

Peripheral neuropathy, peripheral vascular disorder, and infection are three major elements for diabetic foot ulcers that may result in gangrene and amputation. But, peripheral neuropathy is solely chargeable for extra than $80 \%$ of foot ulcers in diabetic patients. This no longer handiest is important for neurological exam because the first criterion for screening patients at risk for foot ulcers, however, is also in a roundabout way emphasized on nurse's position in appearing a diabetic foot examination with monofilament and collaboration with other diabetic foot team participants (Boulton, et al 2018). However, the nurse as educators can evaluate affected person necessities and layout a particular academic application for every of sufferers and their families. Nurses have a powerful function in screening highhazard humans and they also can train patients approximately the significance of everyday visits to the health center, blood tests at exact periods, and the number one principle of diabetes care for prevention of its complication (Ammendola et al., 2017). So, this study will conducted as a penificial for improve foot perfusion and reduce pain level after applying Buerger-Allen Exercises.

\section{Subjects and methods}

Aim of The study:

The current study aimed to evaluate diabetic patients' foot perfusion and their pain level after applying Buerger-Allen Exercises.

Research hypothesis:

There is a significant improvement in diabetic' foot perfusion and their pain level after applying Buerger-Allen Exercises.

\section{Research Design:}

A quasi-experimental research design (study and control groups) was utilized in the current study.

\section{Setting:}

The study conducted at Minia university hospital in the General medical department which was included forty-two beds for patients and a diabetic outpatient clinic that workd on Saturday and Tuesday every week. Minia university hospital is located on the western bank of the Nile River and in the face of the upper bridge on the Nile south of Minia City. The area served was western of Minia city and Minia governorate. It composed of 16 outpatients' clinics and 8 inpatient departments in different medical specialties.

\section{Sample size:}

Purposive sample technique was used to select 100 from adults with type II Diabetes Mellitus who were shared in this study and those who willing were willing and meeting the study inclusion criteria, the study sample was divided equally into control and study (50 patients for each group). The total numbers of patients attending the general medical department and diabetes clinic through the year 2017-2018 were 1000 patients according to hospital statistical office record and the sample were calculated using the following equation:-

$$
\begin{gathered}
N=\frac{t^{2} \times p(1-p)}{m^{2}} \\
N=\frac{(1.96)^{2} \times 0.07(1-0.04)}{0.052}
\end{gathered}
$$

$\mathrm{N}=100$ patients

\section{Description:}

$\mathrm{N}=$ required sample size.

$\mathrm{t}=$ confidence level at $95 \%$ (standard value of 1.960).

$\mathrm{p}=$ estimated prevalence of type 2 diabetes mellitus at Minia University Hospital 2016 (0.07).

$\mathrm{m}=$ margin of error at $5 \%$ (standard value of 0.05 ).

Inclusion criteria:

- Patients who were medically diagnosed with Type II Diabetes Mellitus.

- Ankle Brachial Index (ABI) scored from 0.0-0.40 to less 0.9 


\section{Exclusion criteria:}

- Patients who had severe foot ulcers or amputated. Tools of Data Collection:

The current study data were collected by three tools and 3 tools, the first tool developed by the researcher, and the scales were adopted. The study tool was revised by five experts in the field of nursing at the faculty of nursing (medical surgical nursing department); Assuit and Minia University, to test its face content validity and feasibility, the necessary modifications if present. The current study data collection tools are ....

The first tool: patients' characteristics and their medical data interview questionnaire which included two parts as following:

Part 1: Demographic datasheet of the patients who had type II diabetes mellitus at outpatient clinics. It consised of five (5) items such as age, sex, level of education.

Part 2: medical data of the patients, this part included six (6) questions about medical data as the duration of diabetes, past medical illness history, body mass index, diabetes treatment.....etc.

The second tool: Ankle-brachial index (ABI ) test originally adopted by Winsor (1950), It was defined as the ratio of blood pressure (BP) at the ankle to the $\mathrm{BP}$ in the upper arm(brachium), this test is a simple, non-invasive tool which standard for the diagnosis and screen of lower-extremity (PAD). The ABI test was done individually for every studied subject by using standard manual Sphygmomanometer with appropriately sized cuff(s) for arm and ankle, standard Handheld Doppler device with vascular probe 8.0MHZ and the gel was used to increase conductivity during performing this test.

Calculation of Ankle-brachial Index findings scores $=$ systolic $\mathrm{BP}$ at the ankle / systolic $\mathrm{BP}$ at the brachial in the arm.

\section{Scores Interpretation:}

Above 0.9 - Normal

$0.71-0.90-$ Mild Obstruction.

$0.41-0.70$ - Moderate Obstruction.

$0.0-0.40-$ sever obstruction.

The third tool: Numerical pain rating scale (NPRS)

This scale is a self -report and subjective measure considered the gold standard for pain measurements, usually a horizontal line with numbers from 0 to 10 . The individual asked to circle the number on eleven point numerical scale which corresponding to their pain. The scale is composed of zero (0) which mean no pain at all to ten (10) which means the worst imaginable pain. A description and scoring of this scale a simple form and usually composed of four pain intensity level such as none $=$ zero score, mild $=$ from one to three scores, moderate from four to six scores, and severe from seven to ten scores (Jensen et al. 2001)

- Educational training practices for study group regarding Buerger Allen Exercises:

Buerger-Allen Exercises developed by Burger (1926) and Allen (1930), it was learned by the researcher for the study group, the researcher was given a simple definition and purpose about and its steps. BuergerAllen exercise is Specific exercises intended to improve circulation to the feet and legs. This exercise consisted of three steps; step 1-elevation, the lower extremities elevated to a 45 to 90-degree angle and supported in this position for 2 to 3 minutes until the skin blanched (appears dead white). step 2dependency, the feet, and legs then lowered below the level of the rest of the body for 3 to 5 minutes until redness appears (considering there was no pressure against the back of the knee); step 3-horizontal, the legs are placed flat on the bed for 3-5 minutes. The length of time for each position varied with the patient's tolerance. It's prescribed for 8-13 minutes for a frequency of two times per day and the researcher was informed the study group to repeat it after six weeks of practicing. . Researcher must be assured that this exercise was demonstrated by the studied group incompetent and accurately performance. Also, the researcher has given the study group a brochure in a simple method including pictures regard these exercise steps and instructions regarding duration and frequency to remember the patients or caregiver about this exercise after returning their homes.

\section{Content validity:}

The tools and faced content validity were done to identify the degree it was supposed to be measured. A developed tool, test, and scale were examined by a panel of five experts' opinions in the field of medical and surgical nursing specialty.

Tools reliability:

Internal consistency of the interview questionnaire was assessed with the Cronbach's alpha coefficient. Cronbach's alpha coefficient of 0.00 indicates no reliability and a coefficient of 1.00 indicates perfect reliability. However, a reliability coefficient of $\geq 0.70$ is acceptable. Cronbach's alpha for reliability testing was performed for the first tool, ABI test, and pain scale and the results for the three were $0.897,0.832$ and 0.887 respectively.

Pilot study

To assess the clarity, reliability, and applicability of the study tools which was used in the study for data collection; a pilot study was conducted on $10 \%(\mathrm{n}=10$ diabetic patients) of the sample. Based on the results of the pilot study there is no modification was done. Those cases of the pilot study were included in the study sample. 


\section{Ethical consideration}

Written informed permission was taken from the dean of the faculty for conducting the study. An official letter from the faculty of nursing was delivered to the director (s) of the intended study setting (director of Minia University Hospital, general medical department, and diabetic outpatient clinics). Informed verbal consent was obtained from each diabetic patient who was included in the study. The researcher was provided a full explanation about the about purpose, nature, and tools of the current study for participant patients, informed them individually their rights for privacy by coding, confidentiality, and their rights to withdraw from participation in the study at any time.

\section{The study duration}

The recent study lasted for 12 months; it was started in May 2018 and was completed by the end of April 2019.

\section{Procedure}

- All written and oral permissions were collected then the researcher has selected sample who attended the general medical department and diabetic outpatient clinic. The data collection tool and tests were gathered from the control group firstly through three days per week according to the outpatient schedule, availability of participants lasted four months. While data collection from the study group was started after finishing data collection from the control group by using the same tools.

- In the initiation, for both groups, the second tool (Ankle-brachial index test) was measured and calculated by the researcher to determine patients who have had PVD obstruction and met inclusion criteria in the current study. This test lasted for 20-30 minutes for each participant, upon completing test calculations, compare each reading with the interpretations also the researcher was informed selected both groups that this test would be measured two times pretest as baseline data and after six (6) weeks per six months.

- Ankle-brachial index test was applied by the researcher through using ankle and brachial pressure with Doppler- (BP) cuff tied on the upper arm, palpate the brachial pulse, then place the Doppler after applying gel and inflate at about $20-30 \mathrm{mmHg}$ where a pulse is not audible and then deflate and marked the first heard pulse as the systolic blood pressure and repeat for the other arm. Blood Pressure cuff tied on $2.5 \mathrm{~cm}$ above the malleolus, palpate the dorsalis pedis or posterior tibial pulse, then place the Doppler after applying gel and inflate at about $20-30$ $\mathrm{mmHg}$ where the pulse is not audible and then deflate and mark the first heard pulse as the systolic blood pressure and repeat for the other extremity.

- The pain scale was measured two times for both groups pre-test as baseline data and after six weeks from there including in the current study (to evaluate the effectiveness of exercises on pain measurement for study group only).

\section{Statistical Analysis}

Data were summarized, tabulated, and presented using descriptive statistics in the form of frequency distribution, percentages, means, and standard deviations as a measure of dispersion. A statistical package for the social science (SPSS), version (25) was used for statistical analysis of the data, as it contains the test of significance given in standard statistical books. Numerical data were expressed as mean and SD. Qualitative data were expressed as frequency and percentage. Probability (P-value) is the degree of significance, less than 0.05 was considered significant. The smaller the P-value obtained, the more significant is the result $(*)$, less than 0.001 was considered highly significant $(* *)$, and the correlation coefficient was done by using the Pearson correlation test.

\section{Limitation of the study}

There were some obstacles which encountered the researcher during carrying out the study:-

The difficulty of assembling a large number of diabetic patients at one time.

There is no documentation for peripheral arterial disease cases in the diabetic outpatient clinic 


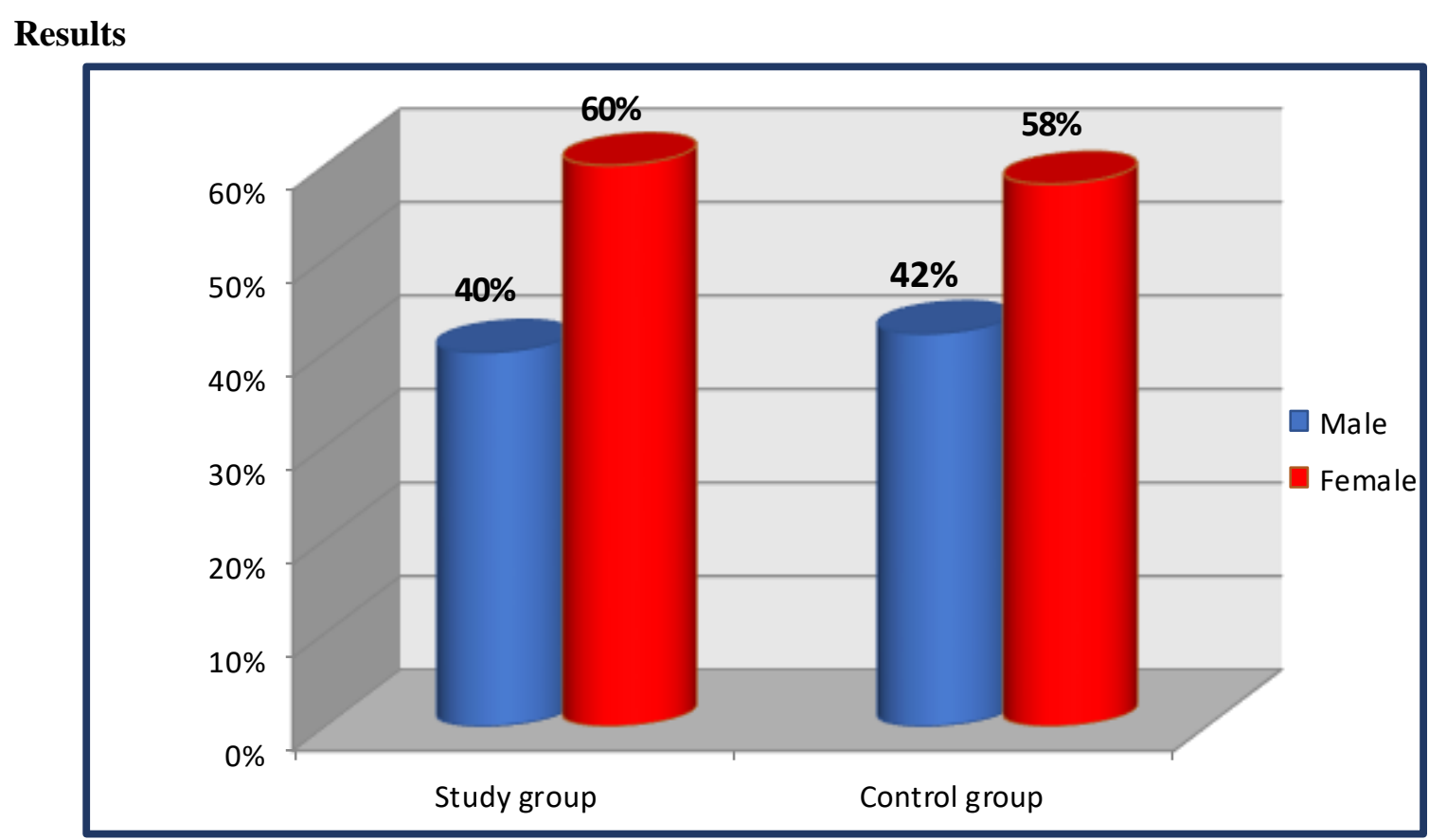

Figure (1): Distribution of the studied sample according to their $\operatorname{sex}(n=100)$.

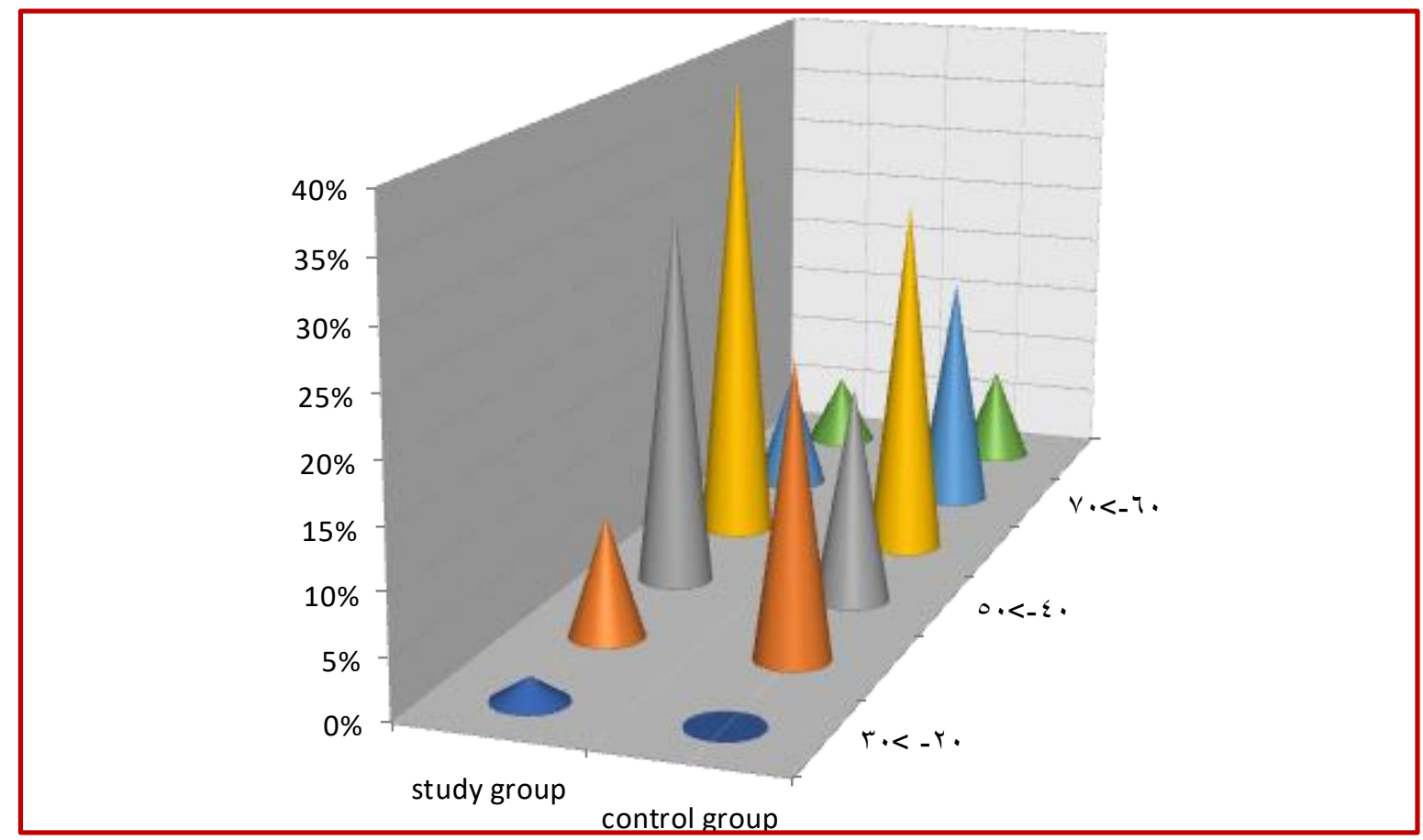

$\square r \cdot<-r . \square \varepsilon \cdot<-r, \square 0 .<-\varepsilon, \square \tau \cdot<-0, \square V \cdot<-\uparrow, \square V \cdot<$

Figure (2): Distribution of the studied sample according to their age $(n=100)$. 
Table (1): Frequency and percentage distribution of the studied sample according to their medical data $(n=100)$.

\begin{tabular}{|c|c|c|c|c|c|c|}
\hline \multirow{3}{*}{ Medical data } & \multicolumn{4}{|c|}{ Groups } & \multirow{3}{*}{$\begin{array}{l}X^{2} / \\
\text { fisher }\end{array}$} & \multirow{3}{*}{$P$-value } \\
\hline & \multicolumn{2}{|c|}{ Study $(N=50)$} & \multicolumn{2}{|c|}{ Control $(\mathrm{N}=50)$} & & \\
\hline & No. & $\%$ & No. & $\%$ & & \\
\hline \multicolumn{7}{|l|}{ Duration of type 2 diabetes } \\
\hline $5-<10$ years & 33 & 66.0 & 32 & 64.0 & \multirow{3}{*}{.046} & \multirow{3}{*}{$.977 \mathrm{NS}$} \\
\hline$>10$ years & 16 & 32.0 & 17 & 34.0 & & \\
\hline Don't know & 1 & 2.0 & 1 & 2.0 & & \\
\hline \multicolumn{7}{|l|}{ BMI } \\
\hline Normal weight & 8 & 16.0 & 14 & 28.0 & \multirow{3}{*}{2.125} & \multirow{3}{*}{$.346 \mathrm{NS}$} \\
\hline Overweight & 32 & 64.0 & 28 & 56.0 & & \\
\hline Obese & 10 & 20.0 & 8 & 16.0 & & \\
\hline \multicolumn{7}{|l|}{ Past medical illness history } \\
\hline Heart disease & 1 & 2.0 & 3 & 6.0 & \multirow{4}{*}{5.191} & \multirow{4}{*}{$.158 \mathrm{NS}$} \\
\hline Hypertension & 19 & 38.0 & 18 & 36.0 & & \\
\hline Heart and hypertension & 4 & 8.0 & 0 & .0 & & \\
\hline Not present & 26 & 52.0 & 29 & 58.0 & & \\
\hline \multicolumn{7}{|l|}{ Diabetes treatment } \\
\hline Oral hypoglycemic agents & 33 & 66.0 & 32 & 64.0 & \multirow{3}{*}{1.306} & \multirow{3}{*}{$.521 \mathrm{NS}$} \\
\hline Insulin & 14 & 28.0 & 17 & 34.0 & & \\
\hline Insulin and oral hypoglycemic agents & 3 & 6.0 & 1 & 2.0 & & \\
\hline \multicolumn{7}{|c|}{ Family history of peripheral arterial disease } \\
\hline Yes & 14 & 28.0 & 17 & 34.0 & \multirow{2}{*}{.421} & \multirow{2}{*}{$.517 \mathrm{NS}$} \\
\hline No & 36 & 72.0 & 33 & 66.0 & & \\
\hline \multicolumn{7}{|l|}{ Receive medical treatment for PAD } \\
\hline Yes & 4 & 8.0 & 3 & 6.0 & \multirow[b]{2}{*}{.154} & \multirow[b]{2}{*}{$.695 \mathrm{NS}$} \\
\hline No & 46 & 92.0 & 47 & 94.0 & & \\
\hline
\end{tabular}

$N S=$ not significant

Table (2): Comparison between the studied patients according to their measurements Anklebrachial index (ABI) scores pre and post six weeks of-application of exercises $(n=100)$.

\begin{tabular}{|l|c|c|c|c|c|c|c|c|}
\hline \multirow{2}{*}{ Items } & \multicolumn{3}{c|}{ Pre-application } & \multicolumn{4}{c|}{ Post application } \\
\cline { 2 - 10 } & \multicolumn{3}{|c|}{ Groups } & \multicolumn{4}{c|}{ Groups } \\
\cline { 2 - 9 } & \multicolumn{2}{|c|}{ Study } & \multicolumn{2}{c|}{ Control } & \multicolumn{2}{c|}{ Study } & \multicolumn{2}{c|}{ Control } \\
\cline { 2 - 9 } & No. & $\mathbf{\%}$ & No. & $\mathbf{\%}$ & No. & \% & No. & \% \\
\hline Ankle-brachial index & & & & & & & & \\
\hline Normal & 0 & .0 & 0 & .0 & 10 & 20.0 & 0 & .0 \\
\hline Mild obstruction & 23 & 46.0 & 30 & 60.0 & 25 & 50.0 & 32 & 64.0 \\
\hline Moderate obstruction & 27 & 54.0 & 20 & 40.0 & 15 & 30.0 & 18 & 36.0 \\
\hline$X^{2} /$ fisher $(P$-value) & \multicolumn{3}{|c|}{$1.967(.161)$ NS } & \multicolumn{3}{c|}{$11.132(.004 * *)$} \\
\hline
\end{tabular}

$\boldsymbol{N S}=$ not significant $\quad * \boldsymbol{p}=\leq \mathbf{0 5}$ (statistical significance $\quad * * \boldsymbol{p}=\leq \mathbf{0 1}$ (highly statistical significance)

Table (3): Relations between frequency\& duration of Buerger Allen exercise application and $\mathrm{ABI}$ measurement among the study group $(n=50)$

\begin{tabular}{|c|c|c|c|c|c|c|c|c|}
\hline \multirow{3}{*}{ Items } & \multicolumn{6}{|c|}{$(\mathbf{A B I})$} & \multirow{3}{*}{$X^{2}$} & \multirow[t]{3}{*}{ P-value } \\
\hline & \multicolumn{2}{|c|}{$\begin{array}{c}\text { Normal } \\
(\mathbf{n}=10)\end{array}$} & \multicolumn{2}{|c|}{$\begin{array}{c}\text { Mild } \\
(n=25)\end{array}$} & \multicolumn{2}{|c|}{$\begin{array}{c}\text { Moderate } \\
(\mathrm{n}=15)\end{array}$} & & \\
\hline & No. & $\%$ & No. & $\%$ & No. & $\%$ & & \\
\hline \multicolumn{9}{|c|}{ Frequency of application per day } \\
\hline $\begin{array}{l}\text { One time/ day } \\
(\mathrm{n}=36)\end{array}$ & 7 & 19.4 & 15 & 41.7 & 14 & 38.9 & \multirow{2}{*}{9.680} & \multirow{2}{*}{$.002 * *$} \\
\hline $\begin{array}{l}\text { Twice or more time/ day } \\
(\mathrm{n}=14)\end{array}$ & 3 & 21.4 & 10 & 71.4 & 1 & 7.2 & & \\
\hline
\end{tabular}




\begin{tabular}{|c|c|c|c|c|c|c|c|c|}
\hline \multirow{3}{*}{ Items } & \multicolumn{6}{|c|}{$(\mathbf{A B I})$} & \multirow{3}{*}{$X^{2}$} & \multirow[t]{3}{*}{ P-value } \\
\hline & \multicolumn{2}{|c|}{$\begin{array}{c}\text { Normal } \\
(\mathbf{n}=10)\end{array}$} & \multicolumn{2}{|c|}{$\begin{array}{c}\text { Mild } \\
(n=25)\end{array}$} & \multicolumn{2}{|c|}{$\begin{array}{c}\text { Moderate } \\
(\mathrm{n}=15)\end{array}$} & & \\
\hline & No. & $\%$ & No. & $\%$ & No. & $\%$ & & \\
\hline \multicolumn{9}{|c|}{ Duration of application } \\
\hline $\begin{array}{l}\text { First two weeks } \\
(\mathrm{n}=16)\end{array}$ & 1 & 6.2 & 8 & 50.0 & 7 & 43.8 & \multirow{3}{*}{7.843} & \multirow{3}{*}{$.02 *$} \\
\hline $\begin{array}{l}\text { Four weeks } \\
(\mathrm{n}=17)\end{array}$ & 2 & 11.8 & 9 & 52.9 & 6 & 35.3 & & \\
\hline $\begin{array}{l}\text { Six weeks } \\
(\mathrm{n}=17)\end{array}$ & 7 & 41.2 & 8 & 47.0 & 2 & 11.8 & & \\
\hline
\end{tabular}

$* \boldsymbol{p}=\leq \mathbf{0 5}$ (statistical significance

$* * \boldsymbol{p}=\mathbf{0 1}$ (highly statistical significance)

Table (4): Frequency and percentage the intensity level of pain description among studied sample pre/post six weeks post application Buerger Allen exercise

\begin{tabular}{|c|c|c|c|c|c|c|c|c|}
\hline \multirow{3}{*}{ Items } & \multicolumn{4}{|c|}{$\begin{array}{c}\text { Pre } \\
\text { Groups }\end{array}$} & \multirow{2}{*}{\multicolumn{4}{|c|}{$\begin{array}{c}\text { Post } \\
\text { Groups }\end{array}$}} \\
\hline & \multicolumn{2}{|c|}{ Study } & \multicolumn{2}{|c|}{ Control } & \multicolumn{2}{|c|}{ Study } & Control & \\
\hline & No. & $\%$ & No. & $\%$ & No. & $\%$ & No. & $\%$ \\
\hline \multicolumn{9}{|l|}{ Pain description } \\
\hline No pain & 7 & 14.0 & 6 & 12.0 & 10 & 20.0 & 0 & .0 \\
\hline Mild pain & 16 & 32.0 & 24 & 48.0 & 25 & 50.0 & 20 & 40.0 \\
\hline Moderate pain & 27 & 54.0 & 20 & 40.0 & 15 & 30.0 & 30 & 60.0 \\
\hline \multicolumn{9}{|l|}{ Severe pain } \\
\hline$X^{2} /$ fisher $(P-$ value $)$ & \multicolumn{4}{|c|}{$1.956(.161) \mathrm{NS}$} & \multicolumn{4}{|c|}{$11.123\left(.004^{* *}\right)$} \\
\hline
\end{tabular}

Table (5): Correlation between exercises' frequency\& duration and total scores for both ABI and pain level measurements among the study group $(n=50)$.

\begin{tabular}{|l|c|c|c|c|}
\hline \multirow{2}{*}{ Exercises } & Ankle-brachial index & \multicolumn{2}{c|}{ Pain } \\
\cline { 2 - 5 } & $\mathbf{R}$ & P-value & R & P-value \\
\hline Frequency of application per day & .214 & .130 & .035 & .795 \\
\hline Duration of application & .390 & $.005^{* *}$ & .128 & .373 \\
\hline
\end{tabular}

**Correlation is significant at the 0.01

Table (6): Relation between personal data of studied sample and their peripheral artery obstruction degree post six weeks of exercise application $(n=100)$.

\begin{tabular}{|c|c|c|c|c|c|c|}
\hline \multirow{4}{*}{ Demographic data } & \multicolumn{6}{|c|}{ Ankle brachial index levels } \\
\hline & \multicolumn{3}{|c|}{ Study } & \multicolumn{3}{|c|}{ Control } \\
\hline & $\begin{array}{c}\text { Normal } \\
(n=10)\end{array}$ & $\begin{array}{c}\text { Mild } \\
(n=25)\end{array}$ & $\begin{array}{c}\text { Moderate } \\
(n=15)\end{array}$ & $\begin{array}{c}\text { Normal } \\
(n=0)\end{array}$ & $\begin{array}{c}\text { Mild } \\
(\mathrm{n}=32)\end{array}$ & $\begin{array}{c}\text { Moderate } \\
(n=18)\end{array}$ \\
\hline & No (\%) & No (\%) & No $(\%)$ & No (\%) & No (\%) & No (\%) \\
\hline \multicolumn{7}{|l|}{ Sex } \\
\hline Male & $5(25.0)$ & $9(45.0)$ & $6(30.0)$ & $(0.0)$ & $14(66.7)$ & $7(33.3)$ \\
\hline Female & $5(16.7)$ & $16(53.3)$ & $9(30.0)$ & $(0.0)$ & $18(62.1)$ & $11(37.9)$ \\
\hline Fisher $(\mathrm{P}-$ value $)$ & \multicolumn{3}{|c|}{$.583(.157) \mathrm{NS}$} & \multicolumn{3}{|c|}{$.112(.738) \mathrm{NS}$} \\
\hline \multicolumn{7}{|l|}{ Age } \\
\hline $20-<30$ & $1(100.0)$ & $0(0.0)$ & $0(0.0)$ & $0(0.0)$ & $0(0.0)$ & $0(0.0)$ \\
\hline $30-<40$ & $2(40.0)$ & $2(40.0)$ & $1(20.0)$ & $0(0.0)$ & $11(91.7)$ & $1(8.3)$ \\
\hline $40-<50$ & $5(31.3)$ & $8(50.0)$ & $3(18.8)$ & $0(0.0)$ & $6(66.7)$ & $3(33.3)$ \\
\hline $50-<60$ & $0(0.0)$ & $12(60.0)$ & $8(40.0)$ & $0(0.0)$ & $8(53.3)$ & $7(46.7)$ \\
\hline $60-<70$ & $1(20.0)$ & $2(40.0)$ & $2(40.0)$ & $0(0.0)$ & $4(40.0)$ & $6(60.0)$ \\
\hline$>70$ & $1(33.3)$ & $1(33.3)$ & $1(33.3)$ & $0 .(0.0)$ & $3(75.0)$ & $1(25.0)$ \\
\hline Fisher $(\mathrm{P}-$ value $)$ & \multicolumn{3}{|c|}{$35.920\left(.000^{* *}\right)$} & \multicolumn{3}{|c|}{$7.465(.113) \mathrm{NS}$} \\
\hline \multicolumn{7}{|l|}{ Educational level } \\
\hline Illiterate & $5(19.2)$ & $16(61.5)$ & $5(19.2)$ & $0(0.0)$ & $\overline{16(61.5)}$ & $10(38.5)$ \\
\hline Read and write & $3(30.0)$ & $5(50.0)$ & $2(20.0)$ & $0(0.0)$ & $9(69.2)$ & $4(30.8)$ \\
\hline Secondary & $2(18.2)$ & $4(36.4)$ & $5(45.5)$ & $0(0.0)$ & $7(63.6)$ & $4(36.4)$ \\
\hline University & $0(0.0)$ & $0(0.0)$ & $3(100.0)$ & $0(0.0)$ & $0(0.0)$ & $0(0.0)$ \\
\hline Fisher $(\mathrm{P}-$ value $)$ & \multicolumn{3}{|c|}{$22.480\left(.000^{* *}\right)$} & \multicolumn{3}{|c|}{$.223(.894) \mathrm{NS}$} \\
\hline
\end{tabular}


Table (7): Relation between the medical status of the studied sample and their peripheral artery obstruction degree post six weeks of exercise application $(n=100)$.

\begin{tabular}{|c|c|c|c|c|c|c|}
\hline \multirow{3}{*}{ Medical status } & \multicolumn{6}{|c|}{ Post ankle brachial index levels } \\
\hline & \multicolumn{3}{|c|}{ Study } & \multicolumn{3}{|c|}{ Control } \\
\hline & $\begin{array}{l}\text { Normal } \\
(n=10)\end{array}$ & $\begin{array}{c}\text { Mild } \\
(n=25)\end{array}$ & $\begin{array}{c}\text { Moderate } \\
(n=15)\end{array}$ & $\begin{array}{c}\text { Normal } \\
(\mathbf{n}=0)\end{array}$ & $\begin{array}{c}\text { Mild } \\
(\mathbf{n}=32)\end{array}$ & $\begin{array}{c}\text { Moderate } \\
(n=18)\end{array}$ \\
\hline \multicolumn{7}{|l|}{ Duration of type II diabetes mellitus } \\
\hline - $5-<10$ years & $7(21.9)$ & $15(46.9)$ & $10(31.3)$ & $0(0.0)$ & $25(78.1)$ & $7(21.9)$ \\
\hline - $>10$ yrs. & $3(17.6)$ & $10(58.8)$ & $4(23.5)$ & $0(0.0)$ & $6(35.3)$ & $11(64.7)$ \\
\hline - Don't known & $0(0.0)$ & $0(0.0)$ & $1(100.0)$ & $0(0.0)$ & $1(100.0)$ & $0(0.0)$ \\
\hline Fisher (P-value) & \multicolumn{3}{|c|}{$25.040\left(.0001^{* *}\right)$} & \multicolumn{3}{|c|}{$9.414\left(.009^{* *}\right)$} \\
\hline \multicolumn{7}{|l|}{ Body mass index (BMI) } \\
\hline - Normal weight & $3(37.5)$ & $3(37.5)$ & $2(25)$ & $0(0.0)$ & $10(71.4)$ & $4(28.6)$ \\
\hline - Overweight & $6(18.8)$ & $17(53.1)$ & $9(28.1)$ & $0(0.0)$ & $17(60.7)$ & $11(39.3)$ \\
\hline - Obese & $1(10.0)$ & $5(50.0)$ & $4(40.0)$ & $0(0.0)$ & $5(62.5)$ & $3(37.5)$ \\
\hline Fisher $(P-$ value $)$ & \multicolumn{3}{|c|}{$\begin{array}{l}1 \\
42.560\left(.001^{* *}\right) \\
\end{array}$} & \multicolumn{3}{|c|}{$.474(.789) \mathrm{NS}$} \\
\hline \multicolumn{7}{|l|}{ Past medical illness history } \\
\hline - Heart disease & $0(0.0)$ & $1(100.0)$ & $0(0.0)$ & $0(0.0)$ & $0(0.0)$ & $3(100.0)$ \\
\hline - Hypertension & $2(10.5)$ & $8(42.1)$ & $2(10.5)$ & $0(0.0)$ & $10(55.6)$ & $8(44.4)$ \\
\hline - Heart and Hypertension & $1(25.0)$ & $2(50.0)$ & $1(25.0)$ & $0(0.0)$ & $0(0.0)$ & $0(0.0)$ \\
\hline - Not present & $7(26.9)$ & $14(53.8)$ & $7(26.9)$ & $0(0.0)$ & $22(75.9)$ & $7(24.1)$ \\
\hline Fisher $(P-$ value $)$ & \multicolumn{3}{|c|}{$68.640(.000 * *)$} & \multicolumn{3}{|c|}{$7.662(.02 *)$} \\
\hline \multicolumn{7}{|l|}{ Diabetes mellitus treatment } \\
\hline - Oral hypoglycemic agents & $8(24.2)$ & $18(54.5)$ & $7(21.2)$ & $0(0.0)$ & $18(56.3)$ & $14(43.8)$ \\
\hline - Insulin & $2(14.3)$ & $6(42.9)$ & $6(42.9)$ & $0(0.0)$ & $14(82.4)$ & $3(17.6)$ \\
\hline - Insulin and oral hypoglycemic agents & $0(0.0)$ & $1(33.3)$ & $2(66.7)$ & $0(0.0)$ & $0(0.0)$ & $1(100.0)$ \\
\hline Fisher $(P-$ value $)$ & \multicolumn{3}{|c|}{$27.640\left(.000^{* *}\right)$} & \multicolumn{3}{|c|}{$5.097(.078) \mathrm{NS}$} \\
\hline \multicolumn{7}{|c|}{ Family history of peripheral arterial disease } \\
\hline - Yes & $1(7.1)$ & $7(50.0)$ & $6(42.9)$ & $0(0.0)$ & $8(47.1)$ & $9(52.9)$ \\
\hline - $\mathrm{No}$ & $9(25.0)$ & $18(50.0)$ & $9(25.0)$ & $0(0.0)$ & $24(72.7)$ & $9(27.3)$ \\
\hline Fisher $(P-$ value $)$ & \multicolumn{3}{|c|}{$9.680(.002 * *)$} & \multirow{2}{*}{\multicolumn{3}{|c|}{$3.209(.073) \mathrm{NS}$}} \\
\hline \multicolumn{6}{|c|}{ Receive medical treatment for peripheral arterial disease (PAD) } & \\
\hline - Yes & $0(0.0)$ & $2(50.0)$ & $2(50.0)$ & $0(0.0)$ & $2(66.7)$ & $1(33.3)$ \\
\hline - $\mathrm{No}$ & $10(21.7)$ & $23(50.0)$ & $13(28.3)$ & $0(0.0)$ & $30(63.8)$ & $17(36.2)$ \\
\hline Fisher $(P-$ value $)$ & \multicolumn{3}{|c|}{$35.280(.0001 * *)$} & \multicolumn{3}{|c|}{$.010(.921) \mathrm{NS}$} \\
\hline
\end{tabular}

Figure (1): Showed that $(60 \% \& 58 \%)$ of the studied sample were females among the study and control groups respectively.

Figure (2): Showed that the mean average age among both groups was around 50 years.

Table (1): Founded that more than two-thirds among both groups had diabetes less than 10 years respectively and they were overweight constituted (64\% \& 56\%) among study and control groups respectively. The result revealed that the highest percentage $(52 \% \& 58 \%)$ among both groups were hadn't any accompanying medical illness. As regard diabetes treatment more than two-third $(66 \%$ \& 64 $\%$ ) among both groups were taken oral hypoglycemic agents but (72\% \&66\%) of them hadn't a Family history of peripheral arterial disease respectively. finally, the majority ( $92 \% \& 94 \%$ ) among both groups weren't received previously any medical treatment for PAD. There were no significant differences between the study and control groups regarding medical data P.> 0.005

Table (2): Showed that there were highly statistically significant differences between the study group and control group regard ABI measurements only postapplication of a Buerger - Allen Exercises for six weeks $(\mathrm{p} \leq 0.004)$.

Table (3): Presented that, $71.4 \%$ of the study group had mild obstruction when they applied the Buerger Allen exercise twice or more time per day for six weeks while(41.7) among the same group was had mild obstruction when they were performed similar exercises one time per day, also table results regard duration of Buerger Allen exercise application revealed that nearly similar percentages 
(50.0\&52.9\&47.0) among study group were had mild obstruction when they were applied Buerger Allen exercise for only two or four or six weeks respectively. So, a statistically significant relation between frequency \&duration of Buerger Allen exercise application and study group' ABI measurement ( $\mathrm{p} \leq 0.002 \& .02$ respectively).

Table (4): Stated that the highest percentage $(54.0 \%)$ among the study group who had moderate pain preapplication exercises but after they were performed exercises, their pain level description became mild or no pain constituted $(50.0 \%$ \& $20.0 \%)$ respectively. There was no statistical difference between pain intensity among the studied sample per application Buerger Allen exercise while post it is application of this exercises there was a highly statistical difference $\mathrm{p}=(.004 * *)$.

Table (5): Showed statistically significant positive relation between an ankle-brachial index of the study group and duration of exercise application which $r=.390$ and $p$-value $>0.005$ but the results related to rest items, not revealed any relation between them.

Table (6): Presented that there was highly statistical significant positive relation between age and education of participated groups data of the study group and their peripheral artery obstruction degree after they applied Buerger Allen exercise for six weeks while were a no statistical significance relation between personal data of the control group and their peripheral artery obstruction degree at $\mathrm{p}=(.004 * *)$.

Table (7): Iindicated that; regarding the study group, it was found that; there were highly statistically significant relation between their peripheral artery obstruction degree and patient's duration of type II diabetes mellitus, body mass index, accompanied medical illness, family history, and received medical treatment. While within the control group; there were no significant differences detected for all items except for the duration of type II diabetes $\mathrm{P} \leq .009$ and the accompanying medical illness $\mathrm{P} \leq .02$.

\section{Discussion}

Diabetes mellitus is a strong risk factor for the improvement of atherosclerotic coronary and which includes ailment of the carotid, aorta, and decreases extremity arterial beds. Peripheral vascular disorder and diabetes are both progressively customary instances; influencing a predicted (two -hundred) and (3-hundred and sixty) million people everywhere in the globe, correspondingly (Berger, \& Ladapo, 2017).

This chapter represents the interpretation and the discussion of the results obtained from the current study. The present study revealed that the mean average age was calculated as $50.9 \pm 10.5$ years and $51.5 \pm 12.53$ years for the study and control group respectively, this related to increasing the risk of peripheral arterial disease among type II diabetes mellitus with the aging process, results were in agreement with John \& Rathiga, (2015) In their study in India found that more than half of both groups between age 51 to 60 years were having lower extremity perfusion with Type II Diabetic. While the results were contradicted with the results of Shilshi, et al., (2017) in their study in Chennai whose found that less than half of diabetic type II patients were between the ages of forty-six to fifty years.

The control group respectively, this can be discussed as decay level of estrogen at menopause cause expanded hazard for diabetes mellitus since estrogen produces several anti-aging impacts counting hostile to oxidative properties as the oxidative stretch is considered the most imperative cause in microvascular diseases. Study results agreed with (Kumar, 2019) who reported that half of the diabetic patients in the experimental group were females. In contrary to the current study findings (Abishal, 2016) in their study in Kanyakumari mentioned that more than half were males.

Results were noted that more than half of the studied sample were females for the study and the study findings indicated that more than half of the studied samples were illiterate, it may be rationalized as in the past there was no interest in education so, and illiteracy was common among diabetic patients that lead to some lack of health awareness about complications of diabetes and its follow up. As well this finding is supported by Bhuvaneshwari, \& Tamilselvi, (2018) in their study in Chennai showed that more than one-third of patients with type II diabetes mellitus were illiterate. Considering the findings of the current study were in contrast with Geethu, (2015) who mentioned that in their study approximately two-thirds of the diabetic patients had school-level education.

Outcomes of the current study showed that more than two-thirds of both groups were having diabetes mellitus from five years to less than 10 years. This can be discussed as the longer the duration of diabetes, the more susceptible to PAD, these results were in agreement with (Patidar, 2018) study found that less than two-thirds of type II diabetic patients were having a duration of diabetes from five to ten years. This finding is in contradiction with (Kumar, et al, 2018) who studied patients with diabetes mellitus in Haryana and mentioned that more than half of the diabetic patients studied samples were having a duration of diabetes mellitus for less than five years.

It was noted that more than two-thirds of the studied samples were overweight/obese, due to lack of compliance with a healthy diet for diabetic patients 
and exercise. In contrast to the current study results from (Kumari, 2019) in their study in Maharashtra and reported that nearly half of the diabetic type II were in the normal range of body mass index. Regarding the family history of peripheral arterial disease more than two-thirds of the study and the control group were with no history. These findings may be due to that diabetes mellitus was caused either by getting old, obese, not exercising regularly, and not eating healthy food. Results were further supported by (Hemalatha, 2018) in their study at Kanniy Akumari district and found that the majority of both groups with type II diabetes mellitus weren't had a family history of peripheral artery disease.

The current study revealed that none of the study of group hadn't have normal brachial index preapplication of exercise while nearly one third among them became normal post its application and more than half were had a moderate level of obstruction pre-application while half of them became mild obstruction in ABI after application of Buerger Allen exercise, it may be attributed to that these postural exercises with alternating emptying and filling of the blood vessels increase circulatory efficiency and local collateral circulation through stimulation of peripheral vascular system.

In the same line the study was consistent with (Shilshi, et al., 2017) illustrated that more than half in the experimental group had moderate PAD whereas later the administration of Buerger Allen training on the level of lower extremity perfusion the majority of the same group had mild PAD among type II diabetes mellitus patients. Also, this finding is congruent with a study done by (Kumar, 2018) who found that more than two-thirds of clients with type II diabetes mellitus had a moderate reduction in peripheral vascular tissue perfusion pre-application of Buerger Allen exercise while more than half among them became mild occlusion of blood vessels after practicing the same exercise.

It was noticed from the current study that there were greatly statistically significant differences among the studied sample regarding peripheral artery obstructions degrees after they were applied Buerger Allen exercise for six weeks and there was no significant difference regarding pre-ankle-brachial index. From the researcher's point of view, it is due to applying Buerger Allen exercise that improves feet and legs circulation. Also other interpretation, it may be because of fear of complications from diabetes and its effect on the foot made patients interested in doing exercise.

This finding was compatible with Saber, et al. (2019) they reported that the post-intervention mean ABI scores of both legs were significantly higher than the pre-intervention score among patients with type II diabetes mellitus after they demonstrated Buerger exercises. This finding also is in agreement with Jacob, (2013) who reported that after the application of Buerger Allen exercise in the experimental group, the posttest mean scores of lower extremity perfusion among Type II DM were highest which was improved than compared to the control group.

Outcomes of the present study indicated that a highly statistically significant improvement in pain level among the study group, from the researcher's point of view, Buerger Allen exercise intended to improve feet and legs circulation that will increase blood flow so that the feeling of pain will decrease. These results are congruent with (Selmar, 2016) in Chennai, which demonstrated that there was a statistically significant difference in the experimental group through diabetes with type II after practicing Buerger Allen exercise regarding their pain. In the same line (Baby, 2015) mentioned that the diabetic patient was decreased pain level after demonstrated Buerger Allen exercise, and t- value was statistically significant.

It is commendable of note that there was a highly statistically significant alteration among the study group concerning the duration of application Buerger Allen exercise; this may be rationalized as the effect of continuity of applying the previously mentioned exercise till six weeks. This result is congruent with Vijayabarathi, (2014) in their study that there was no significant difference in the wound healing process among both groups among the diabetic patients. Regarding the study group, it was found that; there was a highly statistically significant relation between peripheral artery obstructions degrees concerning their age after they applied the Buerger Allen exercise for six weeks. From the researcher's point of view, patients of middle age will be more careful to avoid the occurrence of diabetic foot early and they were have increased in the awareness of the performing and the importance of exercises. This finding is compatible with (Edward, et al., 2011) who said that there was a significant association regarding their age with the ABI results among diabetic and non-diabetic patients. In contrast to the current study results (Kumari, et al., 2019) reported that there wasn't a significant relationship concerning age and ABI between type II diabetes mellitus clients.

Concerning the medical status of the studied sample and their peripheral artery obstructions degrees after they applied Buerger Allen exercise for six weeks, the present study indicated that there were greatly statistically significant differences regarding the duration of type 2 diabetes among both the study and control group. The researcher suggests that may be related to most of the study group had diabetes from 
five years to less than ten years, so when practicing Buerger Allen exercises, it helped them to improve. The results of the current study contradicted with the study of Bhuvaneshwari, \&Tamilselvi, (2018) who pointed out that, there was a significant difference between the duration ration of DM and lower extremity perfusion among patients with type $2 \mathrm{DM}$ regarding the study group after they applied Buerger Allen exercise.

Regarding the study group, it was found that; there was a highly statistically significant relation between peripheral artery obstructions degrees and the family history of peripheral arterial disease after they applied the Buerger Allen exercise for six weeks. This may be rationalized as the genetic factor increases the likelihood of the disease occurring and in the absence of it, the risk of peripheral arterial disease was less. These results in agreement with (Hemalatha, 2018) who conducted that there was a significant association between the posttest levels of lower extremity perfusion and selected clinical variables such as the family history of PAD among patients with type II diabetes mellitus after they demonstrated Buerger Allen exercise.

\section{Conclusion}

The study findings were concluded that Buerger Allen exercise was highly significantly efficient for improvement of lower peripheral arterial perfusion in pain intensity level among them. Also, it was found that; there were highly statistical significance relations between study group age and their education and medical history with peripheral artery obstruction degree after application of exercises.

\section{Recommendations}

Based on the findings of the present study, the following recommendations can be deduced:

1. Diabetic patients must attend health education sessions based on evidence guidelines regard Buerger Allen's exercise which had a positive effect on the improvement of lower peripheral circulation.

2. Share the diabetic patients, Family members, and significant other in planning the care for diabetic patients and encourage them to manage and reduce the complication of diabetes.

3. Encourage the diabetic patients to follow up their ankle-brachial index at least every year to avoid peripheral arterial disease.

4. Organize in-service education programs for staff nurses and students regarding Buerger- Allen exercise and technique for measuring anklebrachial index to monitor PAD occurrence.

5. Conduct the present study on a different probability sample, that are larger and with different socio-demographic features to attain generalization of research results.

\section{References}

- Abishal, A (2016): A Study To Evaluate The Effectiveness Of Buerger-Allen Exercise In Improving The Peripheral Circulation Among Diabetes Patient In Selected Hospital At Kanyakumari District. P 50-59.

- Allen AW. (1930): Recent advanced in the treatment of circulatory disturbance of the extremities: results contained in the peripheral circulatory clinic of the Massachusetts general hospital. Ann Surg ; 92:931-946.

- American Diabetes Association (2017): Prevention or delay of type 2 diabetes. Diabetes Care, 40(Supplement 1), S44-S47

- American Diabetic Association (2017). Acute and Chronic Complications.

- Ammendola, M., Sacco, R., Butrico, L., Sammarco, G., de Franciscis, S., \& Serra, R. (2017): The care of transmetatarsal amputation in diabetic foot gangrene. International wound journal, 14(1), 9-15.

- Baby, B (2015): A study to assess the effectiveness of Buerger Allen exercise on lower extremity perfusion among diabetes mellitus patients admitted in a selected hospital at Coimbatore.P5865

- Berger, J., \& Ladapo, J.(2017): Underuse of prevention and lifestyle counseling in patients with peripheral artery disease. Journal of the American College of Cardiology, 69(18), 2293-2300.

- Bhuvaneshwari, S., \& Tamilselvi, S. (2018): A study to assess the effectiveness of Buerger Allen exercise on lower extremity perfusion among patients with type 2 diabetes mellitus in Saveetha Medical College and Hospital in Chennai. International Journal for Advance Research and Development, 3(9), 15-20.

- Boulton AJM, Armstrong DG, Kirsner RS, (2018). Diagnosis and Management of Diabetic Foot Complications. Arlington, Va., American Diabetes Association, 2018

- Buerger L (1926): The circulatory disturbances of the extremities. Ann Surg ; 83:157.

- Curry, S., Krist, A., Owens, D., Barry, M., Caughey, A., Davidson, K., \& Kubik, M. (2018): Screening for peripheral artery disease and cardiovascular disease risk assessment with the ankle-brachial index: US preventive services task force recommendation statement. Jama, 320(2), 177-183.

- Dauscher, C., \& Molinaro, R. (2017). Complications resulting from uncontrolled diabetes. Medical Laboratory Observer. 
- Edward, B (2011): Diabetes care, Peripheral arterial disease in diabetic and non-diabetic patients- a comparison of severity and complication: vol 24(8)1443-47, Available from http://care.diabetesjournals.org.

- Edwards, S., Svahn, J., Kirk, J., Llaguna, O., \& Habib, N. (2017): Peripheral Vascular Disease in Diabetes. Principles of Diabetes Mellitus, 459-468.

- Geethu, M. (2015): Effectiveness of video-assisted teaching program on the level of knowledge regarding prevention of peripheral vascular disease among diabetic patients admitted in G. Kuppuswamy Naidu Memorial Hospital, Coimbatore (Doctoral dissertation, Apollo College of Nursing, Chennai)

- Gerhard-Herman, M., Gornik, H., Barrett, C., Barshes, N., Corriere, M., Drachman, D., Kinlay, S. (2017): 2016 AHA/ACC guideline on the management of patients with lower extremity peripheral artery disease: executive summary: a report of the American College of Cardiology/American Heart Association Task Force on Clinical Practice Guidelines. Journal of the American College of Cardiology, 69(11), 14651508.

- Gulati, A., Garcia, L., \& Acharji, S. (2017): Epidemiology of chronic critical limb ischemia (pp. 9-14): Springer.

- Saber H. (2019): Effect of Buerger Exercises on Improving Peripheral Circulation of the Lower Extremities among Patients with Type 2 Diabetes Mellitus at Selected University Hospital-Egypt. Indian Journal of Public Health Research \& Development; 10(6): P692-697. Article DOI: 10.5958/0976-5506.2019.01358.5

- Hemalatha, K (2018): effectiveness of Buerger Allen exercise on levels of lower extremity perfusion among patients with type 2 diabetes mellitus in selected hospitals at Kanniyakumari District. P; 60-90

- Jacob, J (2013): Effectiveness of Buerger Allen Exercise on Peripheral Perfusion among patients with Type 2 Diabetes Mellitus in a selected hospital, Bangalore. Rajiv Gandhi University of Health Science, Bangalore

- Jensen, M.P. \& Karoly, P., Turk, D.C., \& Melzack, R. (2001): Handbook of pain assessment.Londres: Guilford.

- John, J, and Rathiga, A (2015): Effectiveness of Buerger Allen exercise to improve the lower extremity perfusion among patients with type 2 Diabetes Mellitus. Int.J.Curr.Res. Acad.
Rev.2015; 3(4):358-366.

- Kumar, AVN (2018): study to evaluate the effectiveness of Buerger Allen Exercise in improving peripheral vascular tissue perfusion among clients with type II diabetes mellitus in selected hospital at Maharashtra.”. International Journal of Science and Research (IJSR); Volume 9 Issue 1, January 2020; p 54-55. www.ijsr.net.

- Kumari A (2019): A study to assess the effectiveness of Buerger Allen exercise on foot perfusion among patients with diabetes mellitus admitted in selected hospital of Ambala, Haryana. Int J Health Sci Res.; 9(1):112-119. www.ijhsr.org

- McDermott, M. (2015): Lower extremity manifestations of peripheral artery disease: the pathophysiologic and functional implications of leg ischemia. Circulation Research, 116(9), 1540-1550.

- Olin, J., White, C., Armstrong, E, KadianDodov, D., \& Hiatt (2016): Peripheral Artery Disease: Evolving Role of Exercise, Medical Therapy, and Endovascular Options J Am Coll Cardiol, 22;67(11):1338-57. doi: 10.1016/j.jacc.2015.12.049.

- Patidar, V. (2018): A study to assess the effectiveness of Buerger-Allenexercise on improving peripheral circulation among type2 Diabetes Mellitus patients in selected hospitals of Nadiad city. Clinical Practice, 15(6), 907-911.

- Selmar, ME (2016): Effectiveness of Buerger Allen Exercise on Lower Extremity Perfusion and Pain among Patients with Type 2 Diabetes Mellitus in Selected Hospitals in Chennai. IJSR. 5(7); July.

- Shilshi, TL (2017): Effectiveness of Buerger Allen exercise on the level of lower extremity perfusion among patients with type 2 diabetes mellitus.saveetha medical college and hospital", International Journal of Development Research, 7, (08), 14723-14726. Available online at http://www.journalijdr.com.

- Thiruvoipati, T., Kielhorn, C., \& Armstrong, E. (2015): Peripheral artery disease in patients with diabetes: Epidemiology, mechanisms, and outcomes. World journal of diabetes, 6(7), 961.

- Vijayabarathi, M (2014): A study to assess the effectiveness of Buerger- Allen exercise on wound healing process among the diabetic foot ulcer patients admitted to the diabetology department at Rajiv Gandhi Government General Hospital. P 65 69.

- Winsor T (1950): Influence of arterial disease on the systolic blood pressure gradients of the extremity. Am J Med Sci.; 220:117-12 